\title{
A ORGANIZAÇÃO DA VIDA E DA REALIDADE ESCOLAR: OLHARES SOB A PERSPECTIVA DAS EXPERIÊNCIAS SOCIOCULTURAIS \\ http://dx.doi.org/10.5902/2318133829684
}

\author{
Daniela Dal Ongaro \\ Unidade de Educação Infantil Ipê Amarelo, Brasil. \\ Doris Pires Vargas Bolzan \\ Universidade Federal de Santa Maria, Brasil. \\ Tasia Fernanda Wisch \\ Universidade Federal do Rio Grande do Sul, Brasil.
}

\begin{abstract}
Resumo
Neste artigo apresenta-se resultados de pesquisa que teve por objetivo foi investigar quais concepções a equipe gestora tem acerca das variáveis socioculturais apresentadas pelos estudantes e como se utiliza destes conhecimentos na organização da vida e realidade escolar dos anos iniciais do ensino fundamental. A metodologia adotada envolveu entrevistas narrativas semiestruturadas e também a análise documental. Assim, identificaram-se as concepções e experiências da equipe escolar em relação à organização da vida e realidade escolar assentada na valorização das alianças de variáveis socioculturais. Contudo, inferimos que o contexto escolar articulado às experiências socioculturais é imperativo na construção de um ensino e de uma aprendizagem dotada de sentido e significado para os estudantes.

Palavras-chave: equipe gestora, vida e realidade escolar, alianças de variáveis socioculturais.
\end{abstract}

\section{THE ORGANIZATION OF LIFE/SCHOOL REALITY: VIEWS UNDER THE PERSPECTIVE OF SOCIOCULTURAL EXPERIENCES}

\section{Abstract}

This paper is part of a monographic research, which aims to investigate what conceptions the management team has about the sociocultural variables of the students and how it uses this knowledge in the organization of life/school reality of the early years of elementary school. For this, the adopted methodology involved semi-structured narrative interviews and also the documental analysis. Thus, it was identified the conceptions and experiences of the school team in relation to the organization of life/school reality based on the valorization of the alliances of sociocultural variables. However, we infer that the school context articulated to the sociocultural experiences is imperative in the construction of teaching and learning endowed with sense and meaning, for the students.

Key-words: management team, life/school reality, alliances of sociocultural variables. 


\section{Introdução}

escola é um espaço de socialização, onde diferentes culturas se encontram e $\triangle$ tecem suas tramas. Nesse lugar as crianças começam as estabelecer Uvínculos, criar hábitos, aprender e ensinar conhecimentos, participar ativamente de um processo educativo que necessita ser imbuído de sentido e significado. Porém, não devemos esquecer que, muito antes de adentrarem a escola, elas passam por constantes e sucessivos processos de aprendizagens que as constituem como um ser social, histórico e cultural. Essas aprendizagens são denominadas por Vygotski (2007) como aprendizado pré-escolar, no sentido de anterioridade da experiência escolar formal.

Em suas singularidades, essas crianças, com suas aprendizagens, trazem para dentro do espaço/tempo escolar suas vivências, suas formas de ver, pensar, sentir e agir no mundo. São elas que, ao conviverem dentro dos muros escolares, dão vida e sentido à escola. Esse convívio, e as relações que ali se estabelecem, é o que formam as alianças de variáveis socioculturais.

Estas, por sua vez, fundamentadas nos pressupostos teóricos de Vygotski (1994, 1998, 2007) Ferreiro (2011) e Bolzan (2009) são compreendidas como

o conjunto de diferentes ideias, conhecimentos, experiências e visões de mundo que os estudantes levam para a sala de aula e que, ao se entrelaçarem, passa a constituir uma trama de "culturas" na "cultura escolar". Logo, essa trama de culturas exerce profunda influência nos modos como os estudantes aprendem, estabelecem relações com os colegas e manifestam seus comportamentos. (Dal Ongaro, 2013, p. 18)

Logo, a influência dessas alianças de variáveis socioculturais é o que orienta os modos de organizar a vida e realidade escolar. Sobre isso Libâneo (2012) entende que as experiências culturais dos indivíduos contribuem para definir a cultura organizacional da instituição de que fazem parte, como é o caso da escola. Nessa direção, podemos compreender que esse entrelaçamento de culturas, ao orientar, definir os modos organizacionais da instituição, acaba também por (trans) formar a cultura escolar. Esta, por sua vez, nos estudos de Bolzan (2009) é definida da seguinte forma:

A escola tem sua própria cultura epistemológica - sua própria maneira de compreender e manifestar a teoria assumida em ação - que pressupõe um conjunto de procedimentos básicos, identificados através das regras educacionais que têm funções tanto sociais quanto cognitivas. Essas regras apresentam o conjunto de convenções escolares e envolvem a normatização do conhecimento escolar, através da definição da rotina escolar/procedimentos, da organização da sala de aula, da listagem de conteúdos, dos tipos de avaliação, compondo o processo de escolarização. (p. 26)

Não somente de uma arquitetura bem planejada e organizada que se caracteriza uma escola, mas também e, principalmente, de valores e de sensibilidade. Valores que afirmem sua função social e sensibilidade para compreender e agir sobre o principal componente que mobiliza a escola: o estudante. É este que necessita de um olhar para além das aparências, de um olhar que consiga compreender suas necessidades, possibilidades e limitações. 
Sob este viés de pensamento, a escola revela-se um espaço de encontro de diferentes culturas. Por assim se constituir, torna-se também uma instituição cultural e, portanto, as relações que nela se estabelecem "não podem ser concebidas como entre dois polos independentes, mas sim, como universos entrelaçados, como uma teia tecida no cotidiano e com fios e nós profundamente articulados" (Moreira; Candau, 2003, p.160). Desse modo é possível enfatizar que, permeada por uma cultura, a escola é detentora de sua própria cultura: a cultura escolar. Sobre isso Moreira e Candau (2003) ainda destacam que

a escola, [...], mais que a transmissora da cultura, da "verdadeira cultura", passa a ser concebida como um espaço de cruzamento, conflitos e diálogo entre diferentes culturas. [...] Tal perspectiva exige que desenvolvamos um novo olhar, uma nova postura, e que sejamos capazes de identificar as diferentes culturas que se entrelaçam no universo escolar, bem como de reinventar a escola, reconhecendo o que a especifica, identifica e distingue de outros espaços de socialização. (p.160)

Diante dessa aliança ou cruzamento que se estabelece entre a escola e o estudante é que formam as alianças socioculturais e que estão imbricados os processos de gestão e organização da vida e realidade escolar.

Nesse sentido, é imprescindível que a equipe gestora observe e compreenda o contexto inicial da constituição e formação humana dos sujeitos: a familia, a sociedade da qual fazem partem, os valores, ritmos e crenças que cada um agrega aos seus modos de viver. Para Vygotski (2007) isso significa considerar que quando a criança entra na escola, ela leva consigo uma história prévia, a qual infere nos seus modos de compreender e apreender os conteúdos escolares.

Assim como outras instituições sociais, a escola é organizada internamente seguindo demandas e objetivos específicos. Por isso, a organização da vida e realidade escolar dos anos iniciais do ensino fundamental precisa ser pensada de modo a valorizar os sujeitos e suas culturas. Insistimos ainda na ideia de que a escola tem como função primordial compreender e considerar a realidade, o cotidiano, os modos de viver e de pensar de seus estudantes. É necessário, portanto, compreendermos o que significa organizar/organização:

organizar significa dispor de forma ordenada, dar uma estrutura, planejar uma ação e prover as condições necessárias para realizá-la. Assim, a organização escolar refere-se aos princípios e procedimentos relacionados a ação de planejar o trabalho da escola, racionalizar o uso de recursos (materiais, financeiros e intelectuais) e coordenar e avaliar o trabalho das pessoas, tendo em vista a consecução de objetivos. (Libâneo, 2012, p. 436)

A partir da interlocução com as ideias propostas por Libâneo (2012) acerca de organização, passamos a entender a organização da vida e realidade escolar como os modos de viver e agir no cotidiano da escola, conformando rotinas, procedimentos, atitudes, valores e objetivos. Nesta organização também estão imbricadas as formas de estruturação do espaço físico, de condições adequadas de higiene e limpeza, da 
administração do tempo escolar, o qual precisa valorizar as especificidades dos alunos, suas condições socioculturais e também materiais. É fundamental, portanto, que a organização geral da escola contemple todos os aspectos da vida escolar (Libâneo, 2012).

Para tanto, é vital que a organização desse espaço seja realizada de modo conjunto, colaborativo, grupal e necessita ser pensada, refletida e formada por toda a equipe gestora, pois esta incide/reflete diretamente no desenvolvimento do trabalho pedagógico em sala de aula e no funcionamento dos demais espaços escolares.

Além disso, as decisões tomadas e as práticas exercidas na escola necessitam de reflexão sobre seu significado, a que valores devem atender e quais as repercussões dessas ações para o futuro.

Diante disso, nos remetemos à organização da vida e realidade escolar, a qual se inicia por meio da construção de um planejamento escolar que, posteriormente, segundo Libâneo (2012) resultará na elaboração de um projeto político-pedagógico da instituição:

O planejamento consiste em ações e procedimentos para tomada de decisões a respeito de objetivos e atividades a serem realizadas em razão desses objetivos. É um processo de conhecimento e análise da realidade escolar em suas condições concretas, tendo em vista a elaboração de um plano ou projeto para a instituição. [...] toda organização precisa de um plano de trabalho que indique os objetivos e os meios de sua execução, superando a improvisação e a falta de rumo. A atividade de planejamento resulta, portanto, naquilo que aqui denominamos de projeto pedagógicocurricular. (p. 470)

No entanto, a construção e organização desse documento necessitam comunicação e vinculação com o mundo exterior. Sobre isso Lück (2011) assevera que

o currículo escolar, que dá unidade e consistência ao trabalho pedagógico da escola, deve ser definido levando em consideração o mundo longínquo, mediato e imediato; remoto e próximo, de modo que o aluno possa conhecer o mundo por meio das experiências que lhe oferece, para nele se situar e nele interagir. Também a metodologia do ensino demanda a problematização e contextualização dos conteúdos na realidade, de modo que os alunos possam perceber a vinculação do que estudam com a realidade, e desenvolver competências para seu enfrentamento. (p. 98)

Com isso, podemos afirmar que o trabalho de elaboração do PPP e do currículo escolar pode se dar de maneira participativa, a partir do exercício de compreensão e reflexão acerca da realidade com a qual se vincula. Contudo, acreditamos que o projeto politico-pedagógico é um caminho de possibilidades rumo ao alcance dos objetivos propostos para organizar a vida e realidade escolar.

É notória a ênfase dada neste trabalho acerca das alianças de variáveis socioculturais, o que nos remete ao fato de que, para organizar uma escola a partir dessas alianças, é necessário que a equipe gestora desenvolva ações de investigação da realidade dos alunos e, posteriormente, planejamento voltado às demandas encontradas. 
Assim, a vida e realidade escolar pode ser pensada, organizada e dinamizada de modo a atender os diversos contextos socioculturais que permeiam o espaço escolar. Para isso é necessário que ocorram práticas de gestão participativa, ou seja, que a equipe escolar esteja envolvida coletivamente.

Desse modo, a estrutura e o funcionamento da instituição ficam sob a responsabilidade de todos os sujeitos que dela fazem parte. Não é compromisso de apenas alguns, mas sim de toda a equipe escolar, pensar, organizar e propor formas de dinamização da vida escolar.

Sob este viés de pensamento é que está assentada a ideia do projeto pedagógicocurricular. Este documento "reflete as intenções, os objetivos, as aspirações e os ideais da equipe escolar, tendo em vista um processo de escolarização que atenda a todos os alunos" (Libâneo, 2012, p. 484), tanto nos aspectos de ensino e de aprendizagem, como nos aspectos socioculturais.

Nesse sentido, percebemos o importante compromisso que a ser firmado pela equipe escolar no momento de investigar e refletir sobre a realidade dos estudantes para a elaboração do PPP. A cada período letivo novas demandas se apresentam e, com isso, novas organizações curriculares, novos olhares ao projeto que visa a atender esses sujeitos que, na escola, buscam complementar a sua formação/constituição humana.

\section{Percurso metodológico}

Para realização desse estudo adotamos como percurso investigativo a abordagem de pesquisa qualitativa. Estudos realizados por Freitas (2002) acerca da pesquisa qualitativa, na perspectiva sócio-histórica, nos permitem compreender que

os estudos qualitativos com o olhar da perspectiva sócio - histórica, ao valorizarem os aspectos descritivos e as percepções pessoais, devem focalizar o particular como instância da totalidade social, procurando compreender os sujeitos envolvidos e, por seu intermédio, compreender também o contexto. (p. 26)

Para contemplar esses aspectos da vida dos sujeitos participantes da pesquisa, lançamos mãos da abordagem narrativa sociocultural. Bolzan (2006) nos ajuda a compreendê-la à medida que a define como um estudo que direciona sua atenção aos processos de construção coletiva, a partir da realidade sociocultural de cada sujeito. Assim, por meio da análise das narrativas é possível realizar uma leitura dos significados impressos sobre as atividades realizadas no âmbito escolar pela equipe gestora.

Essa abordagem proposta utiliza como instrumento para coleta de dados, a entrevista narrativa semiestruturada, a qual permite que o entrevistador faça adaptações que julgar necessárias no desenrolar da conversação. Porém, Lüdke e André (2012) orientam para que o entrevistador não direcione o rumo das respostas, mas proporcione um clima de confiança, em que o narrador sinta-se livre para expressar suas ideias, experiências e crenças acerca do assunto gerativo do diálogo. Por essa razão, acreditamos ser vital compreender o sujeito a partir de sua cultura, pois a singularidade do homem se dá a partir dos elementos e das influências de seu contexto sociocultural. 
Nesse caminho e, com o intuito de melhor conduzir o diálogo no momento da entrevista, ou seja, para a realização da coleta de dados, foram organizados tópicos guia, utilizados no momento da entrevista para seguir um determinado processo reflexivo, atentando para a sequência lógica dos assuntos e respeitando o sentido de seu encadeamento (Lüdke e André, 2012).

$\mathrm{Na}$ sequência, após a realização das entrevistas, as narrativas foram analisadas, visando à interpretação das vozes daqueles sujeitos que participaram da investigação. A partir dessas análises buscamos atribuir sentidos e significados a essas vozes, o que nos permitiu compreender, de maneira subjetiva, os processos que envolvem as práticas de gestão voltadas à valorização das alianças de variáveis socioculturais.

Cabe ressaltar que em relação ao contexto e aos sujeitos da pesquisa as duas escolas selecionadas fazem parte da rede municipal de ensino da cidade de Santa Maria, Rio Grande do Sul, ambas localizadas no bairro Camobi, região Leste da cidade.

Respeitando os padrões éticos da pesquisa, apresentamos nossa proposta às coordenadoras pedagógicas, as quais nos recepcionaram com atenção e cordialidade, aceitando ao convite. Dentre os colaboradores, participaram duas professoras dos anos iniciais do ensino fundamental e duas coordenadoras pedagógicas. Quanto às professoras de cada escola, a indicação para participar partiu das coordenadoras pedagógicas que nos levaram até elas, uma em cada instituição. Dos professores dos anos iniciais, na escola $A$ foi a professora do $2^{\circ}$ ano quem aceitou, já na escola $B$ foi a professora do $1^{\circ}$ ano.

Ainda, para complementar as informações coletadas por meio das narrativas, também consideramos fundamental analisar os documentos legais da escola. Neste caso, selecionamos para a apreciação o projeto político-pedagógico de cada instituição participante. Este tipo de coleta de informações, denominado de análise documental "pode se constituir numa técnica valiosa de abordagem de dados qualitativos, seja complementando as informações obtidas por outras técnicas, seja desvelando aspectos novos de um tema ou problema" (Lüdke; André, 2012, p. 38).

Esse material nos foi disponibilizado após o contato inicial com a equipe gestora das duas escolas participantes e a explicitação do objetivo da pesquisa. Com isso, nos foi dada a oportunidade de analisar e conhecer as normativas que orientam 0 desenvolvimento de práticas pedagógicas alicerçadas na realidade das escolas.

\section{Achados da pesquisa}

Diante dos objetivos propostos para o estudo, da metodologia e dos instrumentos que pautaram a pesquisa, empreendemos uma trajetória de análise em que foi possível observar e refletir acerca dos elementos encontrados nas narrativas coletas durante as entrevistas.

Os dados coletados, a seleção e a análise dos mesmos orientaram à criação de uma grande categoria, sendo esta a gestão da realidade escolar. Tal categoria carrega 0 entendimento acerca de como a equipe gestora organiza o espaço, a vida, a realidade escolar, fundamentada no contexto sociocultural de seus estudantes. Ela foi organizada a 
partir de três dimensões, que emergiram das manifestações recorrentes dos participantes da pesquisa. As dimensões categoriais encontradas foram: a realidade sociocultural e o contexto escolar; a organização da vida e realidade escolar e a constituição do projeto político pedagógico.

A dimensão $A$ realidade sociocultural e o contexto escolar é caracterizada pela compreensão que a equipe gestora possui acerca do que são as vivências socioculturais dos estudantes e como estas influenciam seus modos de ser, pensar e agir no contexto escolar. Sendo essas compreensões oriundas das narrativas, surgiram então quatro elementos categoriais que permeiam essa dimensão. São eles: caminhos adotados para conhecer e compreender a realidade sociocultural dos estudantes; concepções sobre realidade sociocultural; influência da realidade sociocultural no contexto escolar; marcas deixadas por uma escola/família.

Quanto à dimensão $A$ organização da vida e realidade escolar foi permeada pela busca, por parte da equipe gestora, das compreensões sobre a realidade sociocultural dos estudantes para que possam organizar estratégias e criar espaços/tempos que contemplem e atendam as particularidades de seu público estudantil.

Essa dimensão desdobra-se, ainda, com os seguintes elementos: a preocupação com o desenvolvimento dos estudantes e estratégias criadas para sanar as dificuldades apresentadas; o olhar da equipe escolar frente às particularidades dos estudantes.

Já a dimensão Constituição do projeto político pedagógico é configurada a partir da compreensão que a equipe gestora possui acerca de como precisa proceder na elaboração do projeto político-pedagógico.

Encontramos nessa dimensão os seguintes elementos: a vida da escola e a vida dos estudantes como mecanismo de funcionamento do PPP; construção do PPP como ação coletiva sustentada pela vida e realidade escolar.

\section{As dimensões categoriais: análise dos dados coletados}

A categoria Gestão da realidade escolar, que emergiu por meios da análise das entrevistas, é constituída pelos entendimentos, pelas reflexões e pelas ações que a equipe gestora das escolas detém sobre a organização da vida e realidade escolar pautada na realidade de seus estudantes.

A primeira dimensão, caracterizada como a Realidade sociocultural e o contexto escolar, nos possibilitou compreender como a equipe gestora - coordenadora pedagógica e professora - de cada escola participante busca compreensões acerca da realidade sociocultural de seu público estudantil para pensar a organização do contexto escolar.

Podemos conferir legitimidade a essa ideia trazendo o primeiro elemento categorial que permeia essa dimensão: caminhos adotados para conhecer e compreender a realidade sociocultural dos estudantes. Nesse sentido, incluímos as manifestações que sinalizam os caminhos encontrados, pela equipe escolar, para investigar e obter possíveis conhecimentos acerca da realidade vivida por cada estudante. As narrativas que seguem demonstram essa prática:

A conversa, principalmente a conversa com a família. Por exemplo, primeiro ano, a primeira coisa que se faz, lá no início do ano, é uma entrevista com os pais. São alunos novos na escola, a gente não os 
conhece, então pra gente começar a entender eles precisamos fazer uma entrevista, que fica arquivada na escola e que acompanha o aluno sempre, ela fica na pastinha/portfólio de cada aluno. (Coord. L / Escola A)

Os meios que a escola utiliza é uma entrevista, que é feita no primeiro ano (refere-se ao $1^{o}$ ano do ciclo de alfabetização). A professora, até o ano passado ou retrasado, ela suspendia as aulas, ou então ficava...trabalhava meio turno com as crianças e depois, dividia o números de alunos na semana e fazia uma entrevista, bem completa, com a mãe, ou com alguém responsável, onde é perguntado tudo sobre a vida da criança. [...] é uma conversa na verdade, bem assim informal, mas vai anotando "dados" numa ficha que fica no portfólio. (Profa. M / Escola A)

Evidenciamos nessas manifestações que a equipe gestora da escola $A$ utiliza a entrevista com os pais como um instrumento para obter informações básicas sobre seus estudantes, as quais ficam disponíveis ao professor e, certamente, à direção escolar, durante todo $\mathrm{o}$ ano, para que assim as propostas de trabalho e a organização da vida e realidade escolar sejam pensadas a partir deles. Na escola $B$ não é utilizado esse instrumento, porém utilizam 0 diálogo como mecanismo de investigação, de reconhecimento dos seus estudantes. A manifestação seguinte afirma isso:

Nós temos crianças da pré-escola ao $5^{\circ}$ ano, então a maioria dos pais veem até a escola trazer as crianças [...]. Então se houver a necessidade de conversar com a direção, algum recado, nos informar de alguma coisa que está acontecendo com a criança, os pais chegam até a escola, a escola é aberta, eles chegam a hora que eles quiserem na secretaria, eles...as crianças também, a gente tem um entrosamento bem familiar com os pais, então eles tem acesso a escola a hora que eles quiserem. (Coord. $\mathrm{R} /$ Escola B)

Essa narrativa revela que a escola, ao abrir esse espaço de diálogo com os pais, cria condições e estratégias para compreender seus estudantes. Nessa direção, a equipe gestora é imbuída do compromisso de olhar atentamente esses contextos socioculturais que adentram os muros escolares na busca investigativa de compreensão e entendimento acerca dos diferentes modos de ser, pensar e agir de cada um:

Eu acho que é toda a bagagem que ela traz, a história da vida dela, eu imagino que seja, desde bebê. [...]. [...] Então eu acho que é tudo que ela (a criança) traz assim...da vida dela, coisas que as vezes a gente acha que não é importante, mas que fica pra ela. (Profa. M /Escola A)

É a partir dessa compreensão (sobre a realidade de vida) que a gente consegue chegar até o aluno. De nada adianta eu ter uma proposta muito boa de trabalho, sobre a minha perspectiva, se eu não olhar pra realidade do aluno. (Coord. L / Escola A)

Eu acredito sim, que a realidade influencia muito sim. [...] são desses estímulos que eu falo, de leitura, leitura de jornal, as mais diversas... acesso a informatização que hoje em dia é fundamental, então que tem acesso a essa informação, com certeza vai ter um desenvolvimento um pouquinho melhor. (Coord. R / Escola B) 
Essas compreensões caracterizam nosso segundo elemento categorial: Concepções sobre a realidade sociocultural. Desses relatos é possível extrair a importante tese de que os contextos vividos pelos estudantes, fora da escola, incidem diretamente no contexto escolar, provocando a mobilização das coordenadoras e professoras na busca pelo atendimento a essas demandas. Os ditos que seguem também confirmam essa visão:

Influencia muito! A gente quer muito "nivelar as crianças", então às vezes a gente até tem que levar em conta isso né...tem vários casos assim....que...tu não entendes certas coisas, como no ano passado, eu tinha uma turma bem difícil, tive uma menina que foi adotada por várias famílias, e hoje, meu Deus, assim...é um problema e a gente tem que levar em conta essas coisas. [...] Influencia na aprendizagem, em tudo, até na socialização deles (dos alunos), influencia... (Profa. M / Escola A)

O professor planeja uma coisa e, muitas vezes, ele não consegue realizar por causa dessa realidade (do aluno). [...] Por exemplo, tem professores que se queixam da queda no nível de trabalho dele, por exemplo, a professora de artes...as exigências que se faziam a algum tempo atrás, hoje já não podem ser feitas, sabe? Porque o aluno nosso, hoje em dia, embora ele tenha tanto conhecimento, que ele pode ter através de um computador, ele usa cada vez menos pra isso (pra conhecimento). (Coord. L / Escola A)

Nessas narrativas, que caracterizam o terceiro elemento categorial, Influência da realidade sociocultural no contexto escolar, é possível observar e compreender como as vivências de cada estudante fora da escola, influenciam dentro dela.

Com isso tudo permeando a organização da vida e realidade escolar, se torna imprescindível a mobilização e o compromisso de professores, coordenadores e demais funcionários na criação de estratégias e formas de pensar e agir para atender a cada público, a cada contexto, a cada singularidade apresentada. Para que isso se viabilize, Lück (2011) afirma que uma escola deve se configurar pelos modos de ser e de fazer, pela valorização do contexto social que nela está presente, e não somente por suas condições arquitetônicas.

Ao encontro dessas ideias, emerge o quarto elemento categorial dessa dimensão, o qual representa os resultados dessa escola que olha e valoriza as alianças de variáveis socioculturais presentes em seu espaço. Esse elemento emerge das recorrências narrativas que sinalizam marcas deixadas por uma escola/família:

Eu acho que a escola $A$, é uma escola que as pessoas voltam sempre, voltam para nos ver, eu acho que elas têm saudades da escola, eu acho uma escola aconchegante, uma escola que acolhe, sabe? Eu sinto isso. Eu sinto muito isso porque eu trabalho em duas realidades (duas escolas) e noto que aqui...eu acho que eles nunca vão esquecer os profes que tiveram aqui. (Profa. M / Escola $\mathrm{A}$ ).

É bem entrosado mesmo, é uma escola família. A gente costuma dizer a família $B$ (é utilizado o nome da escola)", nós temos a família $B$, por essa abertura que a gente dá pros pais. (Coord. R / Escola B) 
Conseguimos traduzir, por meio dessas manifestações, o significado e as marcas que uma escola pode deixar na vida daqueles que por ela passam, pois não são escolas atentas apenas a ensinar conteúdos e cumprir regras e normativas, mas escolas preocupadas com a constituição de alianças afetivas, formação e desenvolvimento humano alicerçados na confiança, no respeito e no compartilhamento. Porém, essa ação não é algo instantâneo, é um processo que demanda tempo, sensibilidade, envolvimento. Moreira e Candau (2003) afirmam que para realizar essa ação, é de fundamental importância desenvolver um novo olhar, buscando conhecer e compreender as diferenças culturais que vigoram e se cruzam no cenário escolar.

A segunda dimensão categorial é denominada gestão e organização da vida e realidade escolar. Nela estão impressas as formas que a equipe gestora busca organizar em relação a estrutura e o funcionamento da instituição, baseada nas distintas realidades socioculturais presentes nela.

O olhar da equipe gestora frente às particularidades dos estudantes é um dos elementos que sustenta essa segunda dimensão, trazendo como premissa 0 reconhecimento e a valorização das particularidades e necessidades dos estudantes. As colaboradoras relatam que

hoje nós temos uma diversidade muito grande. Nós temos crianças inclusas, incluídas e, os professores. Hoje não se pode mais fazer atividade pra todo mundo da mesma forma, então tu vais ter que ver e compreender que cada aluno é um e é diferente. Então uma das estratégias que as gurias (professoras) estão utilizando agora é um caderno, o caderno de atividades, como forma de atentar....colam no caderno atividades de acordo com o nível de desenvolvimento daquela criança. (Coord. R / Escola B)

Eu acho que a escola assim, às vezes é até bem paternalista, porque tipo o fulano (nome do aluno), um aluno que a gente tem, a gente sabe que vem de outra escola, o autista, vem de uma escola... então assim....eu acho a equipe (professores, diretor, coordenador) bem preocupada com a criança. A gente desconfia, abre uma exceção, ele lancha fora do horário porque a gente sabe que ele vem de outra escola, então ele come naquele horário alí, antes das crianças (antes do horário de rotina). (Profa. M / Escola A)

Tais atitudes evidenciadas nos discursos, embora em contextos diferentes e com outra conotação, são possíveis de serem encontrados também na escola $B$, onde a coordenadora relata a apreensão com as crianças inclusas. Neste cenário há uma preocupação e uma responsabilidade conjunta com as especificidades apresentadas pelos estudantes.

De nada adianta investir em conceitos e fórmulas para os estudantes sem desenvolver a sensibilidade e a preocupação com o modo como eles estão se apropriando disso, sem ao menos aliar esses conhecimentos com a realidade vivida naquele contexto sócio, histórico e cultural. Observamos o que os ditos a seguir nos revelam: 
Eu chego lá (em sala de aula) com uma proposta muito boa pra mim, mas não é pra ele, porque ele não tem uma compreensão cultural e, até da própria realidade, dessa outra realidade que eu quero apresentar pra ele, ele tem a compreensão da realidade dele. Digamos assim: um aluno de "vila", que não sai daqui (desse contexto) e eu falo se sou uma professora de arte...falo de grandes pintores, ele vai ficar sem noção. Agora, claro, eu posso apresentar essa realidade pra ele. Eu posso tirar ele dessa vila que ele está, desse lugar que não tem esse conhecimento, e levar ele a ter esse conhecimento. (Coord. L / Escola A)

Temos crianças com dificuldades de aprendizagem, temos algumas coisas assim, que as gurias (professoras) se preocupam muito: essas crianças que chegam no $3^{\circ}$ ano sem saber ler ainda e já passaram pelas nossas mãos, e não é questão de metodologia; ah é a metodologia daquele professor que não funciona - não é! Porque se ele está na nossa escola, nós estamos desde a pré - escola trabalhando com a perspectiva do letramento, da alfabetização e letramento, o que está acontecendo com

essa criança? Então tem coisas que fogem da nossa alçada. Nós temos uma educadora especial, a gente busca atendimento, conversa com os pais, encaminha pra neurologia, pra fonoaudiologia, pra assistência. (Coord. R / Escola B)

Por meio desses relatos visualizamos o segundo elemento categorial, ou seja, a preocupação com o desenvolvimento dos estudantes e estratégias criadas para sanar as dificuldades apresentadas por eles. Observamos que o envolvimento da equipe escolar está para além de um simples atendimento educacional, essa equipe olha com olhos sensíveis e atentos às necessidades de seus estudantes. Tais mobilizações e ações fortalecem os vínculos e as relações humanas que permeiam o cenário escolar e que por sua vez, constituem as alianças socioculturais.

Na terceira dimensão, Constituição do projeto político pedagógico, encontramos os elementos que sustentam e direcionam a organização da vida e realidade escolar. entendemos, pois, que o PPP é um documento vivo, que necessita do diálogo, da articulação com a realidade escolar para ser posto em ação, para ser desenvolvido, para ser efetivo.

Nas narrativas coletadas evidenciamos que a concepção de projeto políticopedagógico, que consta no referido documento, parte da realidade presente dentro do círculo escolar. Como primeiro elemento categorial surge A vida da escola e a vida dos estudantes como mecanismo de funcionamento do PPP. Atentemos às narrativas seguintes:

Pensando neles (nos alunos), se colocando...justamente...qual que é a realidade da escola? Está ali presente no PPP. Então é um PPP que é real, que acontece todos os dias aquilo ali. Não é uma coisa irreal. [...] é o PPP feito pensando na realidade dos nossos alunos, claro, e quando possível, apresentando outras realidades. (Coord. L / Escola A) 
Desse contato com os pais, é bastante discutido com eles (o projeto político-pedagógico), bastante conversado com eles, pelo conhecimento que a gente tem, pela nossa realidade ser pequena, na verdade não é tão pequena, nós temos 190 alunos, mas a gente consegue ter esse entrosamento com os pais. (Coord. R / Escola B)

O diálogo da equipe gestora na construção do PPP expressa a importância das alianças socioculturais estabelecidas no cenário escolar, deixando evidente que ambas as escolas analisadas levam em conta tais aspectos, uma vez que a elaboração desse documento parte daquilo que a escola é capaz de compreender acerca do contexto da criança. Libâneo (2012) também tece suas contribuições ao divulgar em seus estudos que, para atender a todos os alunos, a equipe gestora necessita ter objetivos e intenções voltadas a eles, os estudantes. Porém, tais objetivos e intenções só podem acontecer quando se conhece a realidade, os diferentes contextos que permeiam a vida e realidade escolar.

Nesse caminho empreendido pela equipe gestora, é importante que também estejam presentes aqueles que formam a base para elaboração do PPP, ou seja, os estudantes e os contextos por eles permeados. Isso, porém, somente acontece quando a escola compreende a importância de aliar sua realidade à realidade de seu público. Para isso, alunos, pais ou responsáveis e comunidade precisam fazer parte desse processo. Nas narrativas abaixo, as quais compõe o segundo elemento categorial dessa dimensão Construção do PPP como ação coletiva sustentada pela realidade escolar, evidenciamos esse movimento:

Os professores participam, a gente pega item por item e a gente constrói juntos. Os pais também, porque foi um questionário pra casa pros pais responderem, tudo tabulado, toda a comunidade escolar. (Profa. M / Escola A)

A sistematização sou eu coordenadora que faço, mas a gente fez questionários para os pais, porque a gente pede uma avaliação deles, como eles estão vendo a escola, como que é o dia a dia da escola, [...] fizemos várias reuniões com professores, com toda a comunidade da escola, com o conselho escolar, eles participam muito, tudo é comunicado, as prioridades que a escola tem, eles participam sempre, tomam as decisões juntos. (Coord. R / Escola B)

Os dados coletados com os pais e alunos para elaboração do PPP auxiliam essa equipe a pensar nas ações e estratégias pedagógicas a serem desenvolvidas no decorrer do ano letivo ao qual se destina o documento. Esses dados, quando coletados, estão em estado bruto e precisam ser lapidados atendendo à vida que acontece dentro da escola. Porém, para que isso aconteça, a equipe gestora necessita discutir e organizar coletivamente os modos e as estratégias cabíveis para que o PPP aconteça no dia a dia da instituição, e não seja apenas mais um documento guardado nos arquivos.

Para aprofundar e complementar nossa compreensão acerca de como a equipe gestora organiza a vida e realidade escolar olhando para os aspectos socioculturais dos estudantes, buscamos no projeto político-pedagógico das escolas participantes, elementos que nos permitissem realizar esse movimento. 
Por meio da leitura, reflexão e análise do PPP de cada escola, e sustentados teoricamente por autores que transitam nesse campo de investigação como Libâneo (2012), Lück (2011), Drabach e Mousquer (2009), constatamos que ambos os documentos são bem estruturados e buscam atender, dentro de seus limites e possibilidades, as alianças de variáveis socioculturais presentes em seu ambiente sociocultural.

Os projetos político-pedagógicos trazem como concepção de educação a premissa de que esta necessita estar voltada aos interesses, necessidades e realidades dos alunos.

Quanto às concepções de gestão foi possível compreender que a escola $A$ busca desenvolver o exercício da democracia, favorecendo a participação, a discussão e a colaboração de todos os segmentos da comunidade no que tange as decisões e encaminhamentos.

$\mathrm{Na}$ escola $\mathrm{B}$, não pudemos realizar uma análise mais acurada dos elementos que constituem as concepções de gestão no PPP, uma vez que não nos foi concedida a autorização para a retirada do projeto de dentro escola.

Decorrente dessas ideias acerca da gestão do espaço/realidade escolar, as escolas possuem prioridades, metas e princípios que a norteiam e que, por sua vez, devem estar expressas no documento legal que a legitima como instituição. Nessa direção, a escola $A$ admite como finalidade o pleno desenvolvimento de seus estudantes, atendendo as normas legais e vigentes, seguindo algumas prioridades, metas e princípios tais como: a igualdade de condições para o acesso e permanência na escola; a compreensão dos direitos e deveres da pessoa humana, do cidadão, do Estado, da família e dos demais grupos que compõem a comunidade; o objetivo de promover a formação básica do cidadão; oferecer ao aluno condições de participação efetiva nas decisões, liberdade e responsabilidade, criatividade, solidariedade e conscientização.

Já a análise do PPP da escola B nos permitiu compreender que em suas metas, princípios e prioridades deve haver a participação da comunidade escolar na elaboração e organização do calendário escolar, bem como na construção de um perfil de escola voltado para a realidade que se faz presente.

Aliado a esses princípios, prioridades e metas buscamos identificar as concepções das coordenadoras e professoras acerca do currículo escolar, segundo o Projeto Político Pedagógico que as sustentam. Verificamos que a escola B constrói seu currículo, alicerçada na compreensão de que este é um caminho a ser trilhado, visando favorecer o aprendizado dos alunos. Para isso, precisa atentar sempre ao contexto social, uma vez que é historicamente situado e culturalmente determinado.

Em relação à escola $A$ esta compreende que no currículo podem ser contempladas todas as experiências escolares que acontecem em torno do conhecimento, nas relações sociais e que colaboram com a construção das identidades dos estudantes.

Pela nossa análise as duas escolas compreendem, portanto, que o currículo precisa estar alicerçado nos entendimentos acerca dos contextos sociais, históricos e culturais dos estudantes para que, dessa forma, seja possível a eles a compreensão e a construção de conhecimentos reais, que valorizem suas especificidades e suas realidades. Dessa forma, os conteúdos podem favorecer a criticidade, a construção da autonomia e a valorização das alianças de variáveis socioculturais.

\begin{tabular}{|l|c|c|c|c|r|} 
Regae: Rev. Gest. Aval. Educ. & Santa Maria & v. 7 & n. 15 & Maio/ago. 2018 & p. 9-24
\end{tabular} 
Dentre os elementos que compõe a análise do PPP das escolas está a organização do tempo escolar, a qual enseja o cuidado para com a comunidade atendida, promovendo condições para que esta consiga participar da construção e desenvolvimento dos processos internos.

A escola B se organiza de forma que as rotinas escolares possam acontecer de maneira flexível, clara, compreensível. Tais rotinas buscam favorecer os processos de desenvolvimento e aprendizagens, atentando aos cuidados físicos, mentais e afetivos indispensáveis para que os ritmos e diferenças individuais sejam respeitados.

$\mathrm{Na}$ escola A o tempo escolar é organizado visando ao cumprimento da legislação vigente, obedecendo ao calendário escolar anual. Este, por sua vez, é discutido junto à comunidade e ao conselho escolar.

Ao nos encaminharmos às últimas análises do documento, focamos na importância das relações estabelecidas entre a escola e a comunidade. Esta apreciação nos direciona a compreensão de que as relações entre ambas são vitais para a construção e desenvolvimento do PPP.

Nas duas instituições verificamos que as relações escola e família, escola e comunidade presupõem o respeito mútuo, a responsabilidade e a participação de cada segmento na elaboração e desenvolvimento das propostas escolares.

Ao final da análise dos PPP das instituições e, respaldados pelas manifestações dos sujeitos colaboradores da pesquisa, evidenciamos certa familiaridade entre ambos os documentos. Eles parecem conversar com as realidades escolares ao articularem seus conhecimentos, seus objetivos e propostas, com as demandas que cada contexto incita. Isso torna o projeto político-pedagógico um documento vivo e real, que se desenvolve nas ações e vivências cotidianas.

\section{Considerações finais}

Compreender como as alianças de variáveis socioculturais dos estudantes podem influenciar na organização da vida e realidade escolar foi o objetivo que engendrou essa pesquisa. Seguindo essa proposta, buscamos conhecer como cada sujeito, detentor de uma cultura, de um saber, de uma crença, pode influenciar dentro de um contexto específico de vivências socioculturais, a escola.

Ao trilhar o caminho metodológico proposto para a pesquisa alcançamos nosso objetivo e verificamos que a equipe gestora de cada instituição busca caminhos para trilhar, visando a entender a realidade de cada estudante. Ainda, entendemos que, o compromisso e a função maior da escola é conseguir compreender a criança e proporcionar a ela, experiências positivas de aprendizagem.

Dessa forma, o diálogo estabelecido com as coordenadoras e a professora, por meios das entrevistas semiestruturadas, nos permitiu elucidar a preocupação delas e de toda a equipe escolar com as especificidades de cada estudante, oriundas de suas condições socioculturais. Isso demonstra 0 olhar da equipe gestora frente as particularidades dos estudantes e a mobilização dessa para atender a essas peculiaridades. 
Também ficaram implícitas, na análise do material coletado, o empenho e a sensibilidade da equipe gestora de cada escola. Mais do que mediar conhecimentos teóricos, os contextos escolares investigados, também buscam olhar e criar estratégias e possibilidades para contemplar em seus processos de ensino e de aprendizagem, todos os estudantes, dos mais variados contextos e condições.

Cabe também afirmar a importância do projeto político-pedagógico. Para tanto, a equipe gestora mostrou-se aberta e receptível a proceder dessa forma na elaboração e dinamização do material, para que, assim, ele ocorra no dia a dia da instituição.

Do conjunto de elementos teóricos que nos permitiu refletir a despeito da construção e prática desse documento, o PPP, sentimos a necessidade de compreender esses contextos investigados na prática cotidiana. Desse modo, nossa pesquisa nos remete à necessidade de prosseguimento, em investigações futuras, objetivando compreender as repercussões desse trabalho, olhando como esse discurso se converte na prática cotidiana.

Analisamos, refletimos e também repensamos nossos entendimentos acerca da organização da vida e da realidade escolar assentada na valorização das alianças de variáveis socioculturais. As instituições por nós acompanhadas durante a investigação manifestam grandes esforços na tentativa de valorizar as alianças de variáveis socioculturais de seus estudantes.

Por fim, nossas inquietações não se encerram neste trabalho, mas lançam novos desafios, na perspectiva de contemplar a inserção no cotidiano das instituições investigadas e aprofundar as compreensões sobre a organização da vida e realidade escolar prática, buscando sempre diminuir as distâncias entre discursos e fazeres pedagógicos.

\section{Referências}

BOLZAN, Dóris Pires V. A construção do conhecimento pedagógico compartilhado: um estudo a partir de narrativas de professores do ensino fundamental. Porto Alegre: Ufrgs, 2001. 280f. Tese (doutorado em Educação). Faculdade de Educação, Universidade Federal do Rio Grande do Sul.

BOLZAN, Dóris Pires V. Formação de professores: compartilhando e reconstruindo conhecimentos. Porto Alegre: Mediação, 2002.

BOLZAN, Dóris Pires V. Narrativa sociocultural. In: MOROSINI, Marília. Enciclopédia de pedagogia universitária. Brasília: Inep, 2006.

DAL ONGARO, Daniela. As variáveis socioculturais como mobilizadoras do planejamento didático do professor. Santa Maria: UFSM, 2013. 95f. Monografia (trabalho de conclusão de curso de Pedagogia). Universidade Federal de Santa Maria.

DRABACH, Neila Pedrotti; MOUSQUER, Maria Elizabete Londero. Dos primeiros escritos sobre administração escolar no Brasil aos escritos sobre gestão escolar: mudanças e continuidades. Currículo sem Fronteiras, v. 9, n. 2, 2009, p. 258-285.

FREITAS, Maria Teresa de Assunção. Abordagem sócio-histórica como orientadora da pesquisa qualitativa. Cadernos de Pesquisa, São Paulo, n. 116, 2000, p. 21-39.

LIBÂNEO, José Carlos; OLIVEIRA, João Ferreira de; TOSCHI, Mirza Seabra. Educação escolar: políticas, estrutura e organização. São Paulo: Cortez, 2012. 
LÜDKE, Menga; ANDRÉ, Marli. Pesquisa em educação: abordagem qualitativa. São Paulo: EPU, 2012.

LÜCK, Heloísa. Gestão da cultura e do clima organizacional da escola. Petrópolis: Vozes, 2011.

MOREIRA, Antonio Flavio Barbosa; CANDAU, Vera Maria. Educação escolar e culturas: construindo caminhos. Revista Brasileira de Educação, n. 23, 2003, p.156-168.

SANTA MARIA. Projeto político-pedagógico. Santa Maria: Smed, 2012.

VYGOTSKI, Lev S. A formação social da mente: o desenvolvimento dos processos psicológicos superiores. São Paulo: Martins Fontes, 1991.

Daniela Dal Ongaro é licenciada em pedagogia e especialista em Gestão Educacional pela Universidade Federal de Santa Maria. Atua como educadora infantil na Unidade de Educação Infantil Ipê Amarelo da Universidade Federal de Santa Maria.

Endereço: Rua Villa Lobos, 12 - 97105-450 - Santa Maria - RS - Brasil.

E-mail: danieladalongaro@hotmail.com.

Doris Pires Vargas Bolzan é professora no Departamento de Metodologia do Ensino do Centro de Educação da Universidade Federal de Santa Maria.

Endereço: Estrada Padre Gabriel Bolzan, 1777, casa 98 - 97095-500 - Santa Maria RS - Brasil.

E-mail: dbolzan19@gmail.com.

Tasia Fernanda Wisch é professora de Educação Especial no Colégio de Aplicação da Universidade Federal do Rio Grande do Sul.

Endereço: Rua Lamartine Babo, 292/2 - 97105-230 - Santa Maria - RS - Brasil.

E-mail: tasiafw@gamil.com.

Recebido em 24 de outubro de 2017.

Aceito em 22 de março de 2018. 